\title{
Modeling sea cage outputs for data-scarce areas: application to red drum (Sciaenops ocellatus) aquaculture in Mayotte, Indian Ocean
}

\author{
Chary Killian ${ }^{1,}{ }^{*}$, Fiandrino Annie ${ }^{2}$, Coves Denis ${ }^{1}$, Aubin Joel ${ }^{3}$, Falguiere Jean-Claude ${ }^{4}$, \\ Callier Myriam ${ }^{1}$
}

1 Univ Montpellier, MARBEC, CNRS, IFREMER,IRD, Palavas Les Flots, France.

2 Univ Montpellier, MARBEC, CNRS, IFREMER,IRD, Sete, France.

3 SAS INRA AGROCAMPUS OUEST, F-35042 Rennes, France.

4 IFREMER, Unite BIODIVENV, Le Robert, Martinique, France.

* Corresponding author : Killian Chary, email address : Killian.Chary@ifremer.fr

\begin{abstract}
:
Robust and accurate prediction of fish farm waste is a first and crucial step in managing the cause-effect chain that leads to local environmental impacts of aquaculture. Since aquatic production is diversifying with new fish species and extending to new areas for which data can be scarce, it is important to develop parsimonious approaches with fewer data requirements and less scientific complexity. We developed the Farm productlon and Nutrient emiSsions (FINS) model, which simulates fish farm operation and estimates fish biomass, feed inputs, and waste emissions from sea cages using simple modeling approaches and a variety of data sources. We applied FINS to red drum (Sciaenops ocellatus) culture in Mayotte by collecting relevant input data (growth, digestibility) from experimental trials. Three explorative farming scenariossmall, medium, and largewere defined from field survey data to examine and compare emissions of a range of potential commercial culture conditions and production scales $(23,299$, and 2079 tyear(-1), respectively). Comparison of the three scenarios showed that waste emissions per ton of fish harvested during routine operations, and thus environmental impacts, were higher for longer culture cycles (medium farm) because of lower feed conversion efficiency. The FINS model is a simple alternative tool to assess and compare environmental impacts of different farming systems and practices for new aquaculture species and regions. It provides important drivers to assess local environmental impacts of fish farms and can therefore facilitate the process of licensing new farming systems for decision-makers.
\end{abstract}

Keywords : Aquaculture waste modeling, CNP mass balance, Farming scenarios, Feed digestibility, Individual-based growth model, Red drum 


\title{
Introduction
}

Aquaculture is the world's fastest-growing food production sector and most diverse farming system in terms of the number of species, methods and environments in which the farms are located (Harvey et al. 2017; FAO 2018). In 2016, global production was 110.2 million t from 598 farmed species, of which 369 were finfishes (FAO 2018). Diversification of species, production systems and spatial distribution of production could provide economic, social and ecological resilience to aquaculture systems in the context of a changing climate, diminishing natural stocks of capture fisheries and other external drivers (Harvey et al. 2017). Diversification will come with development costs, however, including evaluation and mitigation of environmental and social impacts, since future growth needs to be planned in a responsible manner that minimizes these impacts, as claimed for other human activities in international and national directives such as European Water and Marine Strategy Framework directives, the Canadian Oceans Act and the United States National Ocean Policy. In this context, there is increasing adoption of principles of the ecosystem approach to aquaculture (EAA), which provides an holistic planning and management framework, integrating aquaculture activity into its wider socioecosystem (Soto et al. 2008). Implementation of EAA is not straightforward, however, requiring the use of a range of methods and tools, including environmental impact assessment (EIA) (Ferreira et al. 2012a; Byron and Costa-pierce 2013), to help define the type and size of fish farms that can be supported by the environment without leading to unacceptable impact on ecosystem functions and services (i.e. without exceeding ecosystem's ecological carrying capacity).

In environmental sciences, the cause-effect chain of human activities leading to environmental impacts is commonly structured as emission, fate, exposure and effect (Heijungs and Sleeswijk 1999). In marine aquaculture, effluent loads from cages are the emissions of most concern, primarily

\author{
Abbreviations: \\ ADC: Apparent digestibility coefficients \\ $\mathrm{C}, \mathrm{N}$ and P: Carbon, Nitrogen and Phosphorus \\ DEB: Dynamic energy budget \\ DFR: Daily feeding rate \\ EAA: Ecosystem approach to aquaculture \\ EIA: Environmental impact assessment \\ FCR: Feed conversion ratio \\ FINS model: Farm production and nutrient emissions model \\ SGR: Specific growth rate \\ VBGM: Von Bertalanffy growth model
}


containing solid organic particles (feces and uneaten feed) and dissolved inorganic compounds $\left(\mathrm{NH}_{4}{ }^{+}\right.$, $\mathrm{PO}_{4}{ }^{3-}, \mathrm{CO}_{2}$ ). A combination of factors at the farm level (e.g. scale, technology used, feeding, stocking density) and species level (e.g. feed digestibility, feed conversion ratio (FCR)) influences the quantity and quality of wastes. The spatial fate of solid material and its accumulation on the seabed, as well as the transport and dilution of dissolved substances in the ecosystem, are site specific and influenced by local hydrodynamic conditions (i.e. currents and bathymetry). Ultimately, the ecosystem's abiotic characteristics (e.g. water currents, turbulence, temperature, dissolved oxygen, salinity), trophic status (Fernandes et al. 2001) and benthic community ecology will influence the degradation and assimilation of solid and dissolved waste and its associated effects on ecosystem components.

Given the multifactorial nature of these processes, the ecosystem's carrying capacity for aquaculture is usually estimated using complementary tools and models (e.g. growth, farm-scale, hydrological, hydrographic) to provide drivers, boundary conditions or fluxes for larger-scale ecological models (Corner and Aguilar-Manjarrez 2017). In this framework, robust and accurate prediction of fish farm waste using individual growth models and local farm-scale models is a first crucial step. Several farmscale models such as BREAMOD (Brigolin 2007; Brigolin et al. 2010), MOM (Ervik et al. 1997; Kupka Hansen et al. 2001; Stigebrandt et al. 2004) and FARM (Ferreira et al. 2012b) have been developed to simulate species growth and environmental loads to assess site carrying capacity and support management decision. Most of studies and model developments have occurred in Europe and North America and have focused on well-known and commonly produced species such as salmon (Salmo salar), seabream (Sparus aurata) and seabass (Dicentrarchus labrax) (Corner and Aguilar-Manjarrez 2017). Although useful, these modeling approaches require large amounts of high-quality data (i.e. accurate, reliable, up to date and relevant to the context) on species biology, farm configuration, rearing practices and environmental conditions, limiting their application to areas or cases with limited information (Gentry et al. 2017). Indeed, scientific knowledge can remain scarce for newly cultured species, and farm-level and environmental information can be difficult to obtain in data-scarce areas where the aquaculture sector is just emerging.

When data are scarce, a mixed approach combining commercial farm-level data, published studies of biological models and new experimental trials can lead in robust empirical models (Chowdhury et 
al. 2013). Moreover, in regions where the aquaculture sector remains in its infancy, scenario-based investigation, i.e. defining predictive or explorative scenarios (Börjeson et al. 2006) and combining them with a model, can explore a range of waste emissions of potential commercial farming systems and truly support decisions to guide aquaculture development. This kind of ex-ante approach is relevant in developing projects such as red drum (Sciaenops ocellatus) farming in the French overseas department of Mayotte.

Red drum is a euryhaline and eurythermal sciaenid distributed along the Atlantic coast and Gulf of Mexico (Chamberlain et al. 1990). It is popular for fishing activities and has been reared since the late 1970s, but at a small scale. This fast-growing, hardy and disease-resistant species (Sandifer et al. 1993; Lazo et al. 2010) is particularly suitable for marine aquaculture since it can reach a large commercial size. For several French overseas departments in the Caribbean Sea (Martinique and Guadeloupe) and Indian Ocean (Mayotte), red drum has a special importance because it is currently the only finfish species farmed there at a commercial scale.

In 2008, fish from aquaculture was the main product exported from Mayotte. Given Mayotte's high demographic growth (+8\% per year), the aquaculture sector was expected to expand, with a production objective of 550 t by 2020 (Conseil Départemental de Mayotte 2016). Fish farming there is developed within a Marine Nature Park that covers the whole exclusive economic zone and its management plan integrates the development of sustainable aquaculture. However, scientific, technical and economic data on red drum culture, particularly in sea cages and in the tropics, remain scarce. Few relevant data on the fish farms are available since the sector contains only four farms, with total annual production ranging from 30-100 t from 2012-2015. Falguière (2011) summarized knowledge about red drum and recent data obtained in tropical and sub-tropical environments. To our knowledge, only one study has estimated waste emissions of red drum under commercial culture conditions (Xu et al. 2007), and no farm-scale model had been applied to this species until now.

The main objective of this study was to develop a framework to collect and integrate key data in waste simulation models from explorative fish farming scenarios to help in EIA of aquaculture. With this aim, we (1) developed the Farm productIon and Nutrient emiSsions model (FINS), which combines farm production and waste emission modules to predict on-farm biomass dynamics, farm yields and 
waste output (solid, dissolved and C, N, P); (2) applied FINS to red drum culture in the tropics using data (growth, digestibility) from experimental trials; (3) described existing farms through field surveys and built explorative farming scenarios and (4) used FINS to simulate waste emissions of three farming scenarios.

\section{Materials and methods}

\section{Description of the FINS model}

Conceptually, the FINS model is composed of two modules (Figure 1):

(1) Farm production: an individual growth submodel is integrated into a population dynamics framework at cohort and farm levels using data about farm-management practices and cage layout to estimate farm production and feed intake.

(2) Waste emission: A mass-balance submodel of macromolecules is used to predict $\mathrm{C}, \mathrm{N}$ and $\mathrm{P}$ fluxes between feed, fish and waste compartments (uneaten feed, feces, dissolved emissions), and cumulative total solid and dissolved waste emissions during a routine year of production.

The set of equations and parameters used in each module and their units are summarized in Table 1.

$<$ Insert Figure 1 around here >

\section{Farm production module}

We applied the generalized Von Bertalanffy growth model (VBGM) to red drum in warm water conditions. The generalized VBGM (Pauly 1979), like other similar analytical models, does not explicitly consider variations in growth due to fluctuation in limiting (dissolved oxygen) and determining environmental parameters (temperature, salinity, photoperiod), which are generally known to influence fish metabolism greatly (Dumas et al. 2010) and thus growth rates. However, in Mayotte and more generally in the tropics, water temperature is warm and usually varies little among seasons (Jeffs 2013), which can result in high growth rates in species suited to these conditions. For these reasons, and because of the inability to apply a more detailed and complex model due to the scarcity of in-situ environmental data, we chose this simple analytical approach. Furthermore, preliminary analysis 
showed that the VBGM predicted growth more accurately than other analytical models, required few input parameters and is one of the models used most often for fish growth (Katsanevakis 2006; Dumas et al. 2010). In the VBGM, daily fish growth, as a weight-at-age function, is predicted by a nonlinear function with four parameters (Eq. 1 in Table 1). The underlying principles of the VBGM are that growth results from the difference between net anabolism and catabolism, and that growth rate tends to decrease linearly with weight (or length) (von Bertalanffy 1957).

Individual fish growth was integrated into a population dynamic framework that defines fish cohorts whose members have an individual mean weight predicted by the VBGM and are located in the same cage in the cage layout (the latter defined by the number, dimensions and locations of cages). The number of individuals per cohort varies on a daily time step as a function of (1) seeding intensity, (2) natural mortality $\left(\tau_{\text {mort }}\right)$, (3) cultivation loss $\left(\tau_{\text {loss }}\right)$ and (4) the harvesting regime $\left(\tau_{\text {harvest }}\right)$. Losses due to natural mortality are based on a previous survival model developed for red drum in marine cages (Falguière 2011). Cultivation losses account for supplementary losses due to escape, predation and theft, and are a farm-specific factor related to farm scale and rearing practices. Harvesting regime, which is also farm-specific, is null except on the last day of month in which harvest occurs. The number of fish seeded per cage (initial condition) is set to achieve a maximum stocking density of $20 \mathrm{~kg} \mathrm{~m}^{-3}$ in cages during the culture cycle. During a culture cycle, a cohort can be transferred from one cage to a larger one to respect maximum stocking density.

Simultaneous culture of multiple fish cohorts on the same farm is simulated for a routine year of production of a given farm, i.e. using its full nominal capacity with all cages occupied and the maximum number of simultaneous cohorts in production (Figure 2). FINS simulates farm functioning via cohort dynamics and transfers among cages, following a detailed management schedule that describes culture time per cage type and intervals between successive fish cohorts. Routine year of production began after the last cohort was seeded. By summing fish harvests for each cohort over the routine year of production, the model predicts fish biomass production at the farm level. Feed inputs per cage are calculated from daily feeding rate (DFR) and expressed as a percentage of the cage's biomass. The use of DFR to calculate feed inputs allows for dynamic estimation of the total amount of feed distributed to the cages and thus the loss fraction of uneaten feed $\left(\delta_{\mathrm{u}}\right)$. 


\section{$<$ Insert Figure 2 around here > \\ < Insert Table 1 around here >}

\section{Waste emission module}

Quantities of total solid waste and solid and dissolved C, N and P waste from red drum farming are calculated using nutrient mass-balance equations (Table 1). Solid waste estimates include the uneaten fraction of feed and undigested nutrients, while dissolved waste estimates equal the difference between digested nutrients and those retained in fish biomass gain (Cho and Kaushik 1990). Feed inputs are described according to their contents of dry matter, $\mathrm{P}$ and macromolecules (i.e. protein, lipids, carbohydrates (sugars and starch), fiber, ash) based on the proximate composition of each feed in the diet (method described in appendix B). Feed $\mathrm{C}$ and $\mathrm{N}$ contents are estimated using standard stochiometric biochemical equations (Strain and Hargrave 2005) (Eq. 10 in Table 1). Fecal emissions are calculated from apparent digestibility coefficients (ADCs) according to two approaches: (1) the sum of non-digestible macromolecule fractions and (2) non-digestible dry matter in feed (by assuming that total dry weight is the sum of macromolecule fractions). The former calculation approach is more detailed but requires more data than the latter, thus the results obtained with both approaches were compared to determine the value of using a more detailed approach in context of data scarcity. Macromolecules and P retained by fish (harvested, dead or lost) are calculated from fish proximate composition.

\section{Calibration of FINS}

\section{Individual growth submodel calibration and validation}

The VBGM was calibrated using an existing dataset of individual body weight $(n=308)$ of captive red drum broodstock reared for up to 700 days in Martinique from 2004-2008 (Falguière 2011). Fish were reared at a stocking density of $15-20 \mathrm{~kg} \mathrm{~m}^{-3}$ and fed manually with extruded pellets (47\% protein and 13\% lipid). Data collected during Water Framework Directive monitoring programs showed that temperature and dissolved oxygen levels in Martinique and Mayotte waters varied little (Figure 3), from 
$25-31^{\circ} \mathrm{C}$ (corresponding to the temperature preference of red drum) and 5.9-7.0 $\mathrm{mg} \mathrm{l}^{-1}$ (non-limiting for red drum), respectively (Neill 1990; Falguière 2011).

The four VBGM parameters were estimated by minimizing the residual sum of squares between calibration data and predicted weights using the "optim" function of R software (R Core Team 2018). Performance of the calibrated VBGM for Mayotte case study was evaluated by estimating and testing linear regression coefficients (Mesplé et al. 1996) between on farm weight data obtained in Mayotte and predicted weights. The significance of differences of the intercept, slope and coefficient of determination $\left(\mathrm{R}^{2}\right)$ from 1, 0 and 1 respectively, were tested with the Student's t-test. Goodness-of-fit of the submodel was then assessed as "very good", "good", "fair" or "poor" following the classification of Jusup et al. (2009).

$<$ Insert Figure 3 around here >

\section{Determination of nutrient ADCs}

We measured digestibility coefficients experimentally for red drum fed a commercial feed commonly used on farms in Mayotte using an indirect method: coating feed with a indigestible and inert tracer (yttrium oxide) and then measuring tracer and nutrient contents in feed and feces to estimate the digested fraction of nutrients (Hillestad et al. 1999; Austreng et al. 2000). Digestibility trials were performed at the Ifremer Experimental Aquaculture facilities (Le Robert, Martinique, France) with NUTRImarine $6.0 \mathrm{~mm}$ pellets, included in the range of Nutrima ${ }^{\circledR}$ feed $(2.2,3.2,4.5,6.0$ and $9.0 \mathrm{~mm})$ that covers the needs of the whole life-cycle for red drum species. The experiment is detailed in Appendix A. ADCs were calculated (Eq. 12 in Table 1) (Maynard and Loosli 1969) for fractions of total dry matter, macromolecules and elemental P. ADCs and were considered constant during the whole life-cycle of the species. 


\section{Feed and fish body compositions}

Fish body composition was assumed to remain constant during fish growth and thus be identical for seeded, dead, lost and harvested fish even if ontogenic variation in fish body nutrient content has been found in some studies (Pilati and Vanni 2007). Input data used in FINS were mean values over the digestibility trial (Table B.2) using the same commercial feed as that used in FINS. Thus, FINS assumed consistency between fish body composition and feed composition, as recommended by Cho and Bureau (1998). Feed composition data used in FINS were obtained from supplementary analysis of the 5 pellet diameters $(2.2,3.2,4.5,6.0$ and $9.0 \mathrm{~mm})$ of Nutrima ${ }^{\circledR}$ feeds, following the standard methods described in the Appendix A.

\section{From field surveys to farming scenarios}

Surveys were conducted on 8 farms in three French overseas departments having a common regulatory context for aquaculture development - Mayotte (4), Martinique (3) and Guadeloupe (1) - to investigate commercial culture conditions on existing farms and potentially relevant farms for this context so as to characterize and categorize them in a typology. The field surveys, conducted from 2016-2018, provided information about (1) cage layout (number and dimensions) and farm facilities and (2) feeding and rearing practices (e.g. (Lazard et al. 2010)). These data were used to distinguish Small-, Medium- and Large-scale farms in a typology, which was used to build exploratory farming scenarios for FINS (Small, Medium and Large) representing the range of possible commercial farming conditions for red drum in Mayotte. Since French overseas departments do not have Large farms yet, Large farm data were based on an application document for a license to set up a Large farm in Mayotte. Values of key variables retained for each scenario and used in FINS are reported in Table B.3. Given the non-homogeneity of surveys data and its variability in quality, values used for the construction of the three scenarios were determined by expert knowledge based on the range of values collected. 


\section{General setup}

DFRs were obtained from surveys of farms using Nutrima ${ }^{\circledR}$ feed (Table B.1). Values varied monthly and were used to calculate the daily feed inputs during the culture cycle. Uneaten feed was set at 5\% of total feed input (Cromey et al. 2002; Bureau et al. 2003; Hills et al. 2005) in the absence of reliable data for red drum farming. Seeds were introduced in cages at age 40 days (6g according to the VBGM predictions).We calculated mortality rates from the survival model of Falguière (2011), based on 21 red drum genetic families raised for up to 1000 days. Cohort return rates (i.e. percentage of seeded fish that were later harvested) obtained from the surveys were used to set the fish loss rate in each farming scenario.

\section{Sensitivity analysis}

Sensitivity analysis was performed using a one-at-a-time approach to examine the response of FINS output to change in the following input parameters: relative growth rate (k, Eq. 1 in Table 1$), \tau_{\text {loss }}$, maximum stocking density, DFR, $\delta_{\mathrm{u}}$, feed macromolecule contents, feed P and fish P contents (Table 1). For feed macromolecule contents, we only simulated changes in the composition of the NUTRImarine $9.0 \mathrm{~mm}$ pellets, since they were preponderate quantitatively $(64-88 \%$ of annual feed input in Figure B.1) and thus would have more influence on emission predictions than other pellets. After varying default values of each input parameter by $\pm 5 \%$ or $\pm 10 \%$ (depending on the parameter), a normalized sensitivity index (S) was calculated to quantify the change in two model outputs: total solid waste emissions and dissolved $\mathrm{P}$ emissions. $\mathrm{S}$ equaled the relative change in model output divided by the relative change in the input parameter (Gan et al. 2014; Mateus and Franz 2015). The degree of model output sensitivity to each parameter was then classified as "insensitive" ( $\mathrm{S} \leq 0.1)$, "sensitive" $(0.1<\mathrm{S} \leq 1)$, "highly sensitive" $(1<\mathrm{S} \leq 10)$ or "extremely sensitive" $(\mathrm{S}>10)$ (Mateus and Franz 2015). 


\section{Results}

\section{FINS inputs}

\section{Individual growth submodel calibration}

Values of the VBGM parameters with the smallest residual sum of squares were $W_{\infty}=4906.3 \mathrm{~g}, \mathrm{t}_{0}$ $=15$ days, $\mathrm{k}=2.71 \times 10^{-3}$ days $^{-1}$, and $\mathrm{p}=2.493$, respectively. The calibrated VBGM simulated well the weights observed on farms in Mayotte (Figure 4). Linear regression between Mayotte farms data vs predicted weights yielded a slope (0.966), intercept (78.03) and $\mathrm{R}^{2}(0.93)$ that did not differ significantly from 1 (Student's $\mathrm{t}$-test, $\mathrm{t}=0.40, \mathrm{p}=0.70), 0(\mathrm{t}=-0.49, \mathrm{p}=0.64)$ and $1(\mathrm{t}=1.00, \mathrm{p}=0.39)$, respectively, making the VBGM a "very good" predictor.

< Insert Figure 4 around here >

\section{Nutrient ADCs, feed and fish body composition}

The ADCs for NUTRImarine 6.0 pellets (Table 2) were used to calculate fecal emissions for all feeds parameterized in FINS. Feeds varied little in macromolecule composition (Table B.2) and had the same ingredient formulation. During the digestibility experiment, red drum had relatively low FCRs $(1.21 \pm 0.02)$ and high specific growth rates $(0.82 \pm 0.03 \%)$ with the tested diet, as well as high ADCs for dry matter, protein and lipids $(78.0 \pm 1.1 \%, 93.8 \pm 0.7 \%$ and $94.0 \pm 1.5 \%$, respectively). The mean weight of individuals doubled during the 86-day trial, and survival was high $(97 \pm 6 \%)$. Initial and final fish body compositions (Table 2) varied little for all macromolecule fractions analyzed, except for sugars (ranging $0.03 \pm 0.03 \%-0.13 \pm 0.06 \%$ ); thus, mean composition data (Table B.2) were used in FINS to predict nutrient retention as fish grew.

$<$ Insert Table 2 around here > 


\section{Farming surveys and scenarios}

The three production types (Small, Medium and Large farms) differed mainly in scale, farm facilities and fish commercialization sizes. According to this typology, Small farms aimed to supply less expensive products and reduce economic risks for farmers. They had inexpensive floating cages adapted for coastal sites ( $<500 \mathrm{~m}$ from the coast), a short culture cycle ( $\leq 15 \mathrm{months})$ and annual production $<$ $50 \mathrm{t}$. Their return rates ranged from $50-80 \%$. Medium farms had larger but similar rearing facilities as Small ones and aimed to market products from portion-size to $3000 \mathrm{~g}$ per individual, with annual production ranging from 200-1000 $\mathrm{t}$ and return rates ranging from $70-85 \%$. Large farms used circular cages and floating feed storage vessels adapted to offshore aquaculture and aimed to produce $>1500 \mathrm{t}$ of medium-sized fish (about 1500g individuals) per year. On the three types of farms, maximum stocking density varied from $10-20 \mathrm{~kg} \mathrm{~m}^{-3}$. These three types agree with previous descriptions of red drum farms in the Caribbean (Paquotte 1998) and more generally differentiate coastal, off-the-coast and offshore aquaculture farms (Angel and Edelist 2013).

\section{Sensitivity analysis}

Predicted solid waste emission was highly sensitive $(1<\mathrm{S}<10)$ to $\mathrm{ADC}_{\text {protein }}$ and relative growth rate, and sensitive $(0.1<\mathrm{S} \leq 1)$ to DFR and stocking density (Figure 5). In contrast, predicted dissolved $\mathrm{P}$ emission was highly sensitive to changes in DFR, $A D C_{P}$, relative growth rate, $\mathrm{P}$ content in feed $\left(\mathrm{N}_{\mathrm{p}}\right.$

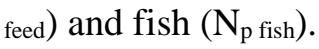

$<$ Insert Figure 5 around here >

\section{Model use}

\section{Predicted farm performance}

Since we did not simulate extreme events (disease, accidents or ecological pulse disturbance), mean biomass during annual routine farm operations on Small, Medium and Large farms varied little throughout the year (around 8, 218 and $756 \mathrm{t}$ of fish respectively), yielding annual production of 23, 
299 and $2079 \mathrm{t}$ of red drum, respectively (Table 3). Based on the simulated DFRs, annual feed inputs were 40, 677 and $3691 \mathrm{t}$ for Small, Medium and Large farms, respectively, leading to FCRs that ranged from 1.54-1.91. The Small farm had a return rate of only $66 \%$, compared to $73 \%$ and $81 \%$ on Medium and Large farms, respectively.

$<$ Insert Table 3 around here >

\section{Solid waste emissions and $C, N$ and $P$ balances}

Predicted annual C, N and P fluxes between feed, fish and waste compartments were calculated per $\mathrm{t}$ of fish harvested per year for the three scenarios (Figure 6). Total C, N and P input from feeding was 16-1477, 3-266 and 0.5-41.9 t, respectively, among scenarios. The percentages of $\mathrm{C}, \mathrm{N}$ and $\mathrm{P}$ in feed released into the environment were $76-82 \%, 72-79 \%$ and $51-64 \%$, respectively, among scenarios. $\mathrm{N}$ was mainly emitted in inorganic dissolved form (85-86\%), as well as C which was primarily emitted via respiration (75-77\%). In contrast, P was almost emitted in solid waste (ca. 54-68\%).

Total annual emission of solid waste varied from $8,878 \mathrm{~kg}$ for the Small farm to $821,098 \mathrm{~kg}$ for the Large farm. Fecal emissions calculated with dry weight ADC or macromolecule ADCs differed little (the latter ca. 2.5\% lower). Per t of fish harvested, Medium farms emitted 1.27 and 1.30 times as much solid waste as Large and Small farms, respectively. Differences were even larger for dissolved C, N and $\mathrm{P}$ emissions, which were respectively $1.33-1.44,1.33-1.45$ and 1.57-2.34 times as large from Medium farms per $t$ of fish harvested than from Large and Small farms.

$$
<\text { Insert Figure } 6 \text { around here > }
$$

\section{Discussion}

\section{Modeling farm waste emissions in the context of data scarcity}

Developing marine aquaculture in Mayotte is perceived as a key priority by local authorities and other stakeholders since it is integrated into regional development programs, and sustainable aquaculture is promoted in Mayotte's Marine Nature Park management plan. However, the fish farming 
industry there remains in its infancy, with a few and economically weak farms, a relative scarcity of insitu monitoring data on fish production and water quality, and little information available on rearing practices. These are major obstacles to the use of detailed and data-intensive farm-scale models to estimate waste emission and their environmental impacts. In this study, we developed an alternative approach using a variety of data sources (e.g. commercial surveys, experiments, literature) to parameterize a simple modular scenario-based model to estimate fish farm production and waste emissions.

Two crucial elements of the FINS model are its ability to predict fish growth and feed requirements accurately, since fish growth is the basis of the model structure (Figure 1), and the parameters involved in predicting growth and feed requirements are the most sensitive parameters of the model (Figure 5). The few existing and relatively outdated growth models available for red drum were not appropriate for our case study because they were either parameterized for wild fish (Doerzbacher et al. 1988; Murphy and Taylor 1990; Ross et al. 1995; Porch et al. 2002) or not operational or relevant for our case study (Neill et al. 2004) given the in-situ data availability and the processes we aimed to simulate. Therefore, we used the VBGM to simulate individual growth, calibrating it with an existing weight-at-age dataset from Martinique. It predicted red drum growth from juvenile $(6 \mathrm{~g})$ to large commercial size (3000 $\mathrm{g})$, and its predictions remain valid for the environmental conditions under which the data were acquired (i.e. water temperature from $25-31^{\circ} \mathrm{C}$ and non-limiting dissolved oxygen concentration $\left(>5 \mathrm{mg}^{-1}\right)$ ). It showed good transposability to a tropical region with similar environmental characteristics, since it well predicted red drum growth from 1.2-2.8 $\mathrm{kg}$ on farms in Mayotte. Feed inputs were estimated using DFRs obtained from commercial farm surveys. While this approach lacks a link to biological mechanisms (DFR can be overestimated, leading to feed losses, or underestimated, which fails to maximize growth potential), it offers realistic estimates of the feed inputs distributed to cages.

In the context of scarce environmental data, and as an initial approach to new aquaculture species, analytical models with fewer input parameters can be a solution to predict simply and effectively fish growth and feed intake under given environmental and rearing conditions. However, since FINS has a modular structure, the sub-models can be exchanged for more detailed models when available, to increase its transposability to biophysical contexts where environmental parameters might vary. In 
environments with significant seasonal or ecological changes in water conditions, integration of more recent energetic approaches such as Ecophys.Fish (Neill et al. 2004), already available for red drum, or Dynamic Energy Budget (DEB) (Kooijman 1986, 2009; Sousa et al. 2010), which is more widely used, would be more suitable. These more detailed models have the advantage to account for interactions of water temperature with fish physiological processes (e.g. maintenance, respiration, excretion, reproduction) but they still do not consider all factors that can influence fish growth or feed intake the most, such as those related to physiological status, nutrition (e.g. feed composition and palatibility), and rearing practices (e.g. feeding frequency, rate and time, stocking density) (Sun et al. 2016).

We provided detailed data essential for estimating accurately waste emissions from fish farms accurately using mass-balance principles, including proximate composition and digestibility of a commercial formulated feed and composition of the fish fed with this feed. The proximate composition of many formulated feeds is well known and easily available from feed manufacturers, but fish proximate compositions and digestibility coefficients are less available for new aquaculture species. As an initial approach, one can refer to values recently reviewed for salmonids, other carnivorous species and omnivorous species (see appendices of Bouwman et al. (2013)). However, feed digestibility, fecal emissions (amount and composition) and nutrient retention of fish are related to feed formulation and nutrient content (Cho and Bureau 1997; Reid et al. 2009), and they can vary as a function, rearing environment, microflora in the aquatic habitat and water temperature, all of which influence development of specific gut flora (Cahill 1990). Thus, significant uncertainties might come from the use of literature data for feed digestibility, particularly given their high sensitivity in output of FINS model. Estimating ADCs with indigestible tracer to parametrize a mass-balance model is relatively easier and cheaper than performing the field experiments necessary to estimate DEB parameters for a new species (four treatment factors and seven response variables) (van der Meer 2006). In the absence of representative data for a given context, feed composition and digestibility should be measured specifically. As long as the data are of good quality, however, simple and parsimonious modeling approaches should be promoted, particularly in a context of data scarcity. Thus, if only solid fecal emissions are needed, they can be estimated from macromolecule digestibility coefficients (6 values needed) or dry matter digestibility ( 1 value needed), with little difference in the output $(<2.5 \%)$. While 
these conclusions should be confirmed for other species and feeds, the latter method is less dataintensive and already used in the DEPOMOD aquaculture impact assessment model (Cromey et al. 2002).

\section{Nutrient balances and farming performances}

Depending on the farm scenario (Large, Medium and Small farms), predicted annual emissions of $\mathrm{C}, \mathrm{N}$ and $\mathrm{P}$ from cages in solid and dissolved forms ranged from 445-639, 76-111 and 8-14 kg, respectively, per $\mathrm{t}$ of fish weight gain and from 528-741, 90-129 and 10-16 kg, respectively, per $\mathrm{t}$ of fish harvested annually. Emissions per t of weight gain were similar to those reported by Bouwman et al. (2013), who reviewed 14 studies with $\mathrm{N}$ balances and 4 studies with $\mathrm{P}$ balances of a variety of marine aquaculture species, including red drum (Xu et al. 2007) and other finfish, in tropical environments (Leung et al. 1999; Tantikitti et al. 2005). On the other hand, only one reference provide farm waste emissions per $t$ of fish harvested annually for marine cage systems (Wang et al. 2012); most other studies expressed emissions per $t$ of fish harvested over a period without explicitly specifying rearing duration and whether waste emission was examined at the cohort or farm level. Depending on the scenario, our predicted emissions were generally higher than Wang et al.'s (2012) estimates for Atlantic salmon (C, N and P emissions $25-46 \%, 45-61 \%$ and 7-43\% higher, respectively), mainly because of the smaller FCR (1.16) of the mature salmon industry than that of red drum in our study (1.54-1.91).

Total nutrient discharge increased with farm size in our scenarios, but standardized to annual farm production during routine operations, Medium and Large farms had relatively the highest and lowest emissions, respectively, because of differences in farm performances and culture practices. Higher emissions from the Small farm than the Large farm (both with a 12-month culture cycle) were due mostly to larger losses on the Small farm. Medium farms had the worst environmental impacts relative to their annual production because of lower FCR due to the longer culture cycle. The longer the culture cycle, the worse the FCR because fish growth rate decreases over time due to using energy for physiological functions besides growth, such as sexual maturity, which appears in red drum from age 1-3 for males and later for females (Murphy and Taylor 1990; Ross et al. 1995). Thus, aquaculture waste emissions per $\mathrm{t}$ of fish harvested in a routine year of production decrease with a shorter culture 
cycle, and local environmental impacts may do so as well. These findings encourage accounting more systematically and precisely for heterogeneity in rearing practices in the modeling of aquaculture waste since it constitutes an important factor of a system's environmental sustainability.

\section{Importance of rearing practices}

Large cultivation losses observed in Mayotte fish farms and modeled in the scenarios include escapes and predation, which are primarily engineering and management challenges to adapt facilities to external factors (i.e. wind, waves, bird and fish predation), but they also include theft, which is a real threat for small-scale fish farming in Mayotte. The logistical advantage and more remote location of offshore systems (Large farm) may decrease theft and vandalism but also farm accessibility, which is not an option for Small farms. Since large losses are a major problem for a farm's profitability and potential environmental impacts (genetic interactions and risk of competition with wild stocks) (Jackson et al. 2015), the development of sustainable and more productive aquaculture in Mayotte might come from better control of rearing practices, increasing the security of rearing facilities and the establishment of maritime security by institutional maritime authorities.

Aquaculture local environmental impacts per $t$ of fish harvested in a routine year of production was reduced with shorter culture cycle, but it is likely that longer culture cycles are more profitable for farmers. Indeed, producing larger fish in longer culture cycles reduces fingerling costs per $\mathrm{kg}$ of marketed fish. Producing larger fish also allows for first-stage processing (fish filet or steak), which adds value to the product. Therefore, in terms of economic profitability, lower FCR in longer culture cycles may be balanced by benefits to fingerling costs and prices of processed products. However, these questions lay beyond the scope of this study; addressing them would require assessing and comparing the financial feasibility of different rearing practices and including a general economic indicator of resource use efficiency. 


\section{Conclusion}

This study presented a compromise between data requirements and scientific complexity to estimate fish farm production and waste emissions in the context of data scarcity. The combination of parsimonious mathematical models using a variety of data sources and a scenario-based approach can provide an operational approach to assess and compare environmental impacts of different farming systems and practices for new aquaculture species and regions.

In Europe, EIA of aquaculture at the local scale is a crucial step in the licensing of new fish farms. Solid waste has the greatest environmental impact immediately around the farm because it can accumulate on the seabed and cause benthic organic enrichment. However, potential environmental risks and impacts depend greatly on the specific biophysical context of the farm, which makes it difficult to avoid a site-by-site evaluation and to establish site-specific recommendations for a given farm at a wider spatial scale. Further research is therefore needed to characterize the main physical, chemical and ecological factors at the regional scale that influence local environmental impacts of aquaculture in order to provide a broad view of these impacts, which could facilitate site selection and the licensing process for decision-makers.

\section{Acknowledgement}

This study was undertaken as a part of a Ph.D. thesis in the CAPAMAYOTTE project, Phase 2 (2015-2018), supported by the Natural Marine Park of Mayotte and the Mayotte County Council. The authors gratefully acknowledge the members of UM Ifremer Martinique for helping collect experimental data. We also thank Paul Giannasi for his involvement in the survey work and all the fish farmers who participated in this study. The authors thank Dr. E. Roque d'Orbcastel and Dr. T. Laugier for reading and editing the manuscript prior to submission and Dr. M.S. Corson for careful revision of the English. 


\section{Appendix A}

\section{Description of the digestibility trial with red drum}

The commercial diet tested in this study was composed mainly of soybean, fish meal, wheat and fish oil and contained $48 \%$ protein and $13 \%$ lipids. The pellets were first coated with yttrium oxide (yttrium oxide and cod oil at $1 \%$ of feed weight each) as an inert tracer to determine apparent digestibility coefficients. The animals were 124-day-old ( $84 \mathrm{~g}$ mean body weight, BW) laboratory farmed red drum, originating from captive broodstock. On Day $-42\left(\mathrm{D}_{-42}\right)$, fish (mean BW 83-85 g) were individually weighed and randomly divided into 3 treatment groups of 30 fish, each group placed in a tank to become acclimated to the experimental environment. Beginning on $\mathrm{D}_{-20}$, fish (mean BW 145-156 g) were fed with NUTRImarine 4.5 pellets. On $\mathrm{D}_{0}$, initial individual fish weighed 206-216 g (mean $211 \mathrm{~g}$ ), and each group was adjusted to 26 individuals. Each group was reared in a $1 \mathrm{~m}^{3}$ indoor tank supplied with $1 \mathrm{~m}^{3}$ $\mathrm{h}^{-1}$ of filtered seawater in a flow-through system. Water salinity was 37.0. PSU, and oxygen concentration always exceeded $80 \%$ saturation. Temperature was $27.5 \pm 0.5^{\circ} \mathrm{C}$ with artificial lighting of $160 \mathrm{~lx}$ at the water surface (12 h:12 h L:D cycle, lights on at 6:00 a.m.).

Feed was manually delivered once a day at 8:30 am to each group until satiation. Feed intake of each group was calculated daily as a percentage of each group's biomass. A sediment trap (150 1 each) located at the outlet of each tank was checked for uneaten pellets, and feed loss was considered nil during the experiment.

Feces were collected twice a day $(4: 00 \mathrm{pm}$ and 8:00 pm) in the sediment trap via a siphon system for nine days $\left(\mathrm{D}_{73}-\mathrm{D}_{75}, \mathrm{D}_{78}-\mathrm{D}_{82}\right.$ and $\left.\mathrm{D}_{85}\right)$ and frozen. Fish scales were removed from samples, and then feces were concentrated by centrifugation and freeze-dried before analysis.

At $\mathrm{D}_{0}, \mathrm{D}_{21}, \mathrm{D}_{42}, \mathrm{D}_{63}$ and $\mathrm{D}_{85}$ (last day of the trial), feeding was stopped for $24 \mathrm{~h}$, and then fish were individually weighed. A representative sample of whole fish $(n=6)$ was withdrawn from each treatment group at $\mathrm{D}_{0}$ (initial) and $\mathrm{D}_{91}$ (final) and kept frozen $\left(-20^{\circ} \mathrm{C}\right)$ until analysis of body composition. Whole fish bodies were pooled, ground and freeze-dried before chemical analysis.

Red drum whole-body samples, feed pellets and feces were analyzed following standard procedures: dry matter after drying at $105^{\circ} \mathrm{C}$ for $24 \mathrm{~h}$, protein $(\mathrm{N} \times 6.25)$ by the Kjeldahl method after acid hydrolysis, lipids after extraction with petroleum ether by the Soxhlet method, sugar by the Luff-Schoorl method, 
starch by the Ewers polarimetric method, fiber from fraction analysis by the Van Soest method and ash by ignition. Yttrium contents were measured in feed and fecal samples by atomic absorption spectrophotometry using a nitrous oxide-acetylene flame, after acid digestion (2\% nitric acid and $2 \mathrm{~g} \mathrm{l}^{-}$ $\left.{ }^{1} \mathrm{KCl}\right)$. 


\section{Appendix B}

Table B.1. Daily feeding rate (DFR) and pellet diameter used to calculate feed inputs for red drum (Sciaenops ocellatus) culture in a warm water environment $\left(25-31^{\circ} \mathrm{C}\right)$ in the Farm productIon and Nutrient emiSsions (FINS) model and obtained from surveys of farms feeding using commercial Nutrima ${ }^{\circledR}$ feed $(2.2,3.2,4.5,6.0$ and $9.0 \mathrm{~mm})$.

\begin{tabular}{ccc}
\hline $\begin{array}{c}\text { Month in the } \\
\text { culture cycle }\end{array}$ & $\begin{array}{c}\text { DFR } \\
\left(\% \text { of biomass.d }{ }^{-1}\right)\end{array}$ & $\begin{array}{c}\text { Pellet diameter } \\
(\mathrm{mm})\end{array}$ \\
\hline 1 & 5.25 & 2.2 \\
2 & 3.00 & 3.2 \\
3 & 2.30 & 4.5 \\
4 & 1.90 & 6.0 \\
5 & 1.75 & 6.0 \\
6 & 1.65 & 9.0 \\
7 & 1.20 & 9.0 \\
8 & 1.15 & 9.0 \\
9 & 1.10 & 9.0 \\
10 & 1.05 & 9.0 \\
11 & 0.95 & 9.0 \\
12 & 0.90 & 9.0 \\
13 & 0.85 & 9.0 \\
14 & 0.70 & 9.0 \\
15 & 0.60 & 9.0 \\
16 & 0.55 & 9.0 \\
17 & 0.50 & 9.0 \\
18 & 0.45 & 9.0 \\
19 & 0.40 & 9.0 \\
20 & 0.35 & 9.0 \\
\hline & &
\end{tabular}

Table B.2. Proximate compositions of commercial feed $\left(\mathrm{N}_{\mathrm{i}}\right.$ feed $)$ by pellet diameter and red drum (Sciaenops ocellatus) $\left(\mathrm{N}_{\mathrm{i} \text { fish }}\right)$ used in the Farm productIon and Nutrient emiSsions (FINS) model. Raw values were obtained by analysis and then recalculated for $100 \%$ of dry matter assuming that total dry weight (DW) was the sum of protein, lipid, sugar, starch, fiber and ash fractions.

\begin{tabular}{lccccccc} 
& \multicolumn{6}{c}{ Feed by pellet diameter (mm) } & Red drum \\
\cline { 2 - 7 } Composition & 2.2 & 3.2 & 4.5 & 6.0 & 9.0 & $\begin{array}{c}\text { Whole-body } \\
\text { composition }\end{array}$ & Unit \\
\hline Dry weight & 94.00 & 95.14 & 89.18 & 90.7 & 86.51 & 30.04 & $(\%)$ \\
Protein & 51.01 & 49.74 & 52.51 & 51.24 & 51.50 & 58.68 & (\% DW) \\
Lipids & 13.35 & 15.45 & 13.83 & 14.03 & 13.45 & 22.37 & (\% DW) \\
Sugars & 1.69 & 2.25 & 2.16 & 2.72 & 2.68 & 0.08 & (\% DW) \\
Starch & 14.64 & 14.16 & 12.79 & 13.37 & 13.69 & 0.00 & (\% DW) \\
Fiber & 11.33 & 10.48 & 9.85 & 9.38 & 10.00 & 0.00 & (\% DW) \\
Ash & 7.97 & 7.92 & 8.85 & 9.25 & 8.67 & 13.76 & (\% DW) \\
Phosphorus & 1.57 & 1.26 & 1.34 & 1.24 & 1.30 & 2.58 & (\% DW) \\
\hline
\end{tabular}


Table B.3. Values of key parameters used in the Farm productIon and Nutrient emiSsions (FINS) model for three scenarios of red drum farming: Small, Medium and Large.

\begin{tabular}{|c|c|c|c|c|}
\hline Parameter & Small & Medium & Large & Unit \\
\hline \multicolumn{5}{|l|}{ Population size } \\
\hline Seeding & 10,400 & 34,500 & 69,400 & $\begin{array}{l}\text { Individuals } \\
\text { per cohort }\end{array}$ \\
\hline$\tau_{\text {mort }}$ & 0.0527 & 0.0516 & 0.0527 & $\%$. day $^{-1}$ \\
\hline$\tau_{\text {loss }}$ & 0.0986 & 0.0082 & 0.0082 & $\%$. day $^{-1}$ \\
\hline \multicolumn{5}{|l|}{$\tau_{\text {harvest }}{ }^{\mathrm{a}}$} \\
\hline 6 & 5.00 & - & - & $\%$. day $^{-1}$ \\
\hline 7 & 10.00 & - & - & $\%$. day $^{-1}$ \\
\hline 8 & 25.00 & - & - & $\%$. day $^{-1}$ \\
\hline 9 & 45.00 & - & - & $\%$. day $^{-1}$ \\
\hline 10 & 60.00 & - & 20.00 & $\%$. day $^{-1}$ \\
\hline 11 & 70.00 & - & 50.00 & $\%$. day $^{-1}$ \\
\hline 12 & 95.40 & - & 98.15 & $\%$. day $^{-1}$ \\
\hline $13-15$ & - & 10.00 & - & $\%$. day $^{-1}$ \\
\hline $16-18$ & - & 15.00 & - & $\%$. day $^{-1}$ \\
\hline 19 & - & 40.00 & - & $\%$. day $^{-1}$ \\
\hline 20 & - & 98.18 & - & $\%$. day $^{-1}$ \\
\hline \multicolumn{5}{|l|}{ Farm management } \\
\hline Culture cycle & 12 & 20 & 12 & months \\
\hline Cage layout & $\begin{array}{l}6 \text { rectangular } \\
(6 \mathrm{~m} \mathrm{~L} \times 6 \mathrm{~m} \mathrm{~W} \times 4 \\
\mathrm{m} \mathrm{H})\end{array}$ & $\begin{array}{l}4 \text { rectangular } \\
(7 \mathrm{~m} \mathrm{~L} \times 7 \mathrm{~m} \mathrm{~W} \times 8 \\
\mathrm{m} \mathrm{H}) \\
6 \text { rectangular } \\
(14 \mathrm{~m} \mathrm{~L} \times 14 \mathrm{~m} \mathrm{~W} \times \\
13 \mathrm{~m} \mathrm{H})\end{array}$ & $\begin{array}{l}6 \text { circular } \\
(12 \mathrm{~m} \mathrm{D} \times 6 \mathrm{~m} \mathrm{H}) \\
24 \text { circular } \\
(20 \mathrm{~m} \mathrm{D} \times 12 \mathrm{~m} \mathrm{H})\end{array}$ & \\
\hline Seeding schedule & $\begin{array}{l}1 \text { cohort every } 4 \\
\text { months }\end{array}$ & $\begin{array}{l}1 \text { cohort every } \\
2-3 \text { months }\end{array}$ & $\begin{array}{l}2 \text { cohorts every } \\
\text { month }\end{array}$ & \\
\hline $\begin{array}{l}\text { Number of } \\
\text { simultaneous } \\
\text { cohorts }\end{array}$ & 3 & 8 & 24 & \\
\hline
\end{tabular}

${ }^{\mathrm{a}}$ Harvest rate was set daily, but was null except on the last day of month in which harvest occurred 
Figure B.1. Sizes of feed pellets simulated in three red drum farm scenarios (Small, Medium and Large), expressed as percentages of total annual feed inputs. 
Conflict of Interest: The authors declare that they have no conflict of interest.

Ethical statement: All applicable international, national, and/or institutional guidelines for the care and use of animals were followed by the authors. 


\section{References}

Angel D, Edelist D (2013) Sustainable development of marine aquaculture off-the-coast and offshore - a review of environmental and ecosystem issues and future needs in tropical zones. In A. Lovatelli, J. AguilarManjarrez \& D. Soto, eds. Expanding mariculture farther offshore: tec. In: FAO Fisheries and Aquaculture Proceedings No. 24. Rome, pp 173-200

Austreng E, Storebakken T, Thomassen MS, et al (2000) Evaluation of selected trivalent metal oxides as inert markers used to estimate apparent digestibility in salmonids. Aquaculture 188:65-78. doi: 10.1016/S00448486(00)00336-7

Börjeson L, Höjer M, Dreborg K-H, et al (2006) Scenario types and techniques: Towards a user's guide. Futures 38:723-739. doi: 10.1016/J.FUTURES.2005.12.002

Bouwman AF, Beusen AHW, Overbeek CC, et al (2013) Hindcasts and future projections of global inland and coastal nitrogen and phosphorus loads due to finfish aquaculture. Rev Fish Sci 21:112-156. doi: $10.1080 / 10641262.2013 .790340$

Brigolin D (2007) Development of integrated numerical models for the sustainable management of marine aquaculture. Università Ca' Foscari Venezia

Brigolin D, Pastres R, Tomassetti P, Porrello S (2010) Modelling the biomass yield and the impact of seabream mariculture in the Adriatic and Tyrrhenian Seas (Italy). Aquac Int 18:149-163. doi: 10.1007/s10499-0089232-4

Bureau DP, Gunther SJ, Cho CY (2003) Chemical Composition and Preliminary Theoretical Estimates of Waste Outputs of Rainbow Trout Reared in Commercial Cage Culture Operations in Ontario. N Am J Aquac 65:33-38. doi: 10.1577/1548-8454(2003)065<0033:CCAPTE>2.0.CO;2

Byron CJ, Costa-pierce B a (2013) Carrying capacity tools for use in the implementation of an ecosystems approach to aquaculture. In: Ross LG, Telfer TC, Falconer L, et al. (eds) Site selection and carrying capacity for inland and coastal aquaculture. FAO/Institute of Aquaculture, University of Stirling, Expert Workshop, 6-8 December 2010. Stirling, UK. FAO Fisheries and Aquaculture Proceedings No. 21, Rome, pp 87-101

Cahill MM (1990) Bacterial flora of fishes: A review. Microb Ecol 19:21-41. doi: 10.1007/BF02015051

Chamberlain GW, Miget RJ, Haby MG (1990) Red drum aquaculture. In: Symposium on the culture of red drum and other warm water fishes. p 240

Cho C, Bureau D (1998) Development of bioenergetic models and the Fish-PrFEQ software to estimate production, feeding ration and waste output in aquaculture. Aquat Living Resour 11:199-210. doi: 10.1016/S0990-7440(98)89002-5

Cho CY, Bureau DP (1997) Reduction of waste output from salmonid aquaculture through feeds and feeding. Progress Fish-Culturist 59:155-160. doi: 10.1577/1548-8640(1997)059<0155:ROWOFS>2.3.CO;2

Cho CY, Kaushik SJ (1990) Nutritional energetics in fish: energy and protein utilization in rainbow trout (Salmo gairdneri). In: World Reviews in Nutrition and Dietetics. Karger Publishers, pp 132-172

Chowdhury MAK, Siddiqui S, Hua K, Bureau DP (2013) Bioenergetics-based factorial model to determine feed requirement and waste output of Tilapia produced under commercial conditions. Aquaculture 410411:138-147. doi: 10.1016/J.AQUACULTURE.2013.06.030

Conseil Départemental de Mayotte (2016) Plan strategique du developpement durable de l'aquaculture a mayotte (PSDDAM) 2014-2020. Mamoudzou, Mayotte

Corner RA, Aguilar-Manjarrez J (2017) Tools and Models for Aquaculture Zoning, Site Selection and Area Management. In J. Aguilar-Manjarrez, D. Soto \& R. Brummett. Aquaculture zoning, site selection and area management under the ecosystem approach to aquaculture. Rome, FAO, and World Bank Group, Washington, DC. 395 pp

Cromey CJ, Nickell TD, Black KD (2002) DEPOMOD—modelling the deposition and biological effects of waste solids from marine cage farms. Aquaculture 214:211-239. doi: 10.1016/S0044-8486(02)00368-X

Doerzbacher JF, Green AW, Matlock GC, Osburn HR (1988) A temperature compensated von bertalanffy 
growth model for tagged red drum and black drum in Texas bays. Fish Res 6:135-152. doi: 10.1016/01657836(88)90033-1

Dumas A, France J, Bureau D (2010) Modelling growth and body composition in fish nutrition: where have we been and where are we going? Aquac Res 41:161-181. doi: 10.1111/j.1365-2109.2009.02323.x

Ervik A, Hansen' PK, Aure J, et al (1997) Regulating the local environmental impact of intensive marine fish farming I. The concept of the MOM system (Modelling-Ongrowing fish farms-Monitoring). Aquaculture 158:85-94

Falguière J-C (2011) L’ombrine ocellée, Sciaenops ocellatus : biologie, pêche, aquaculture et marché, Quae. Savoir faire

FAO (2018) The State of World Fisheries and Aquaculture 2018 - Meeting the sustainable development goals. Rome

Fernandes, Eleftheriou, Ackefors, et al (2001) The scientific principles underlying the monitoring of the environmental impacts of aquaculture. J Appl Ichthyol 17:181-193. doi: 10.1046/j.14390426.2001.00315.x

Ferreira JG, Aguilar-Manjarrez J, Bacher C, et al (2012a) Progressing aquaculture through virtual technology and decision-support tools for novel management. In: Subasinghe RP, Arthur JR, Bartley DM, et al. (eds) Global Conference on Aquaculture 2010, Phuket, Thailand. 22-25 September 2010. FAO, Rome and NACA, Bangkok, pp 643-704

Ferreira JG, Saurel C, Ferreira JM (2012b) Cultivation of gilthead bream in monoculture and integrated multitrophic aquaculture. Analysis of production and environmental effects by means of the FARM model. Aquaculture 358-359:23-34. doi: 10.1016/j.aquaculture.2012.06.015

Gan Y, Duan Q, Gong W, et al (2014) A comprehensive evaluation of various sensitivity analysis methods: A case study with a hydrological model. Environ Model Softw 51:269-285. doi: 10.1016/J.ENVSOFT.2013.09.031

Gentry RR, Lester SE, Kappel C V, et al (2017) Offshore aquaculture: Spatial planning principles for sustainable development. Ecol Evol 7:733-743. doi: 10.1002/ece3.2637

Harvey B, Soto D, Carolsfeld J, et al (2017) Planning for aquaculture diversification: the importance of climate change and other drivers. In: FAO Technical Workshop, 23-25 June 2016, FAO Rome. FAO Fisheries and Aquaculture Proceedings No. 47, Rome, p 166

Heijungs R, Sleeswijk AW (1999) Letters to the Editor: comment and reply comment the structure of impact assessment: mutually independent dimensions as a function of modifiers. Int J LCA 4:2-3

Hillestad M, Åsgård T, Berge GM (1999) Determination of digestibility of commercial salmon feeds. Aquaculture 179:81-94. doi: 10.1016/S0044-8486(99)00154-4

Hills A, Spurway J, Brown S, Cromey C (2005) Regulation and Monitoring of Marine Cage Fish Farming in Scotland - Annex H - Methods for Modelling In-feed Anti-parasitics and Benthic effects

Jackson D, Drumm A, McEvoy S, et al (2015) A pan-European valuation of the extent, causes and cost of escape events from sea cage fish farming. Aquaculture 436:21-26. doi: 10.1016/J.AQUACULTURE.2014.10.040

Jeffs AG (2013) A review on the technical constraints, opportunities and needs to ensure the development of the mariculture sector worldwide - tropical zone. In A. Lovatelli, J. Aguilar-Manjarrez \& D. Soto, eds. Expanding mariculture farther offshore: technical, environm. In: FAO Fisheries and Aquaculture Proceedings No. 24. Rome, FAO, pp 101-133

Jusup M, Klanjšček J, Petricioli D, Legović T (2009) Predicting aquaculture-derived benthic organic enrichment: Model validation. Ecol Modell 220:2407-2414. doi: 10.1016/j.ecolmodel.2009.06.033

Katsanevakis S (2006) Modelling fish growth: Model selection, multi-model inference and model selection uncertainty. Fish Res 81:229-235. doi: 10.1016/J.FISHRES.2006.07.002

Kooijman SALM (1986) Energy budgets can explain body size relations. J Theor Biol 121:269-282. doi: 10.1016/S0022-5193(86)80107-2

Kooijman SALM (2009) Dynamic energy budget theory for metabolic organisation, third edition 
Kupka Hansen P, Ervik A, Schaanning M, et al (2001) Regulating the local environmental impact of intensive, marine fish farming II. The monitoring programme of the MOM system (Modelling-Ongrowing fish farms-Monitoring). Aquaculture 194:75-92

Lazard J, Baruthio A, Mathé S, et al (2010) Aquaculture system diversity and sustainable development: fish farms and their representation. Aquat Living Resour EDP Sci 23:187-198. doi: 10.1051/alr/2010018

Lazo JP, Holt JG, Fauvel C, et al (2010) Drum-fish or Croakers (Family: Sciaenidae). In: Le François N, Jobling M, Carter C, Blier P (eds) Finfish aquaculture diversification, First edit. CABI, pp 398-417

Leung KMY, Chu JCW, Wu RSS (1999) Nitrogen budgets for the areolated grouper Epinephelus areolatus cultured under laboratory conditions and in open-sea cages. Mar Ecol Prog Ser 186:271-281. doi: $10.3354 /$ meps 186271

Mateus M, Franz G (2015) Sensitivity Analysis in a Complex Marine Ecological Model. Water 7:2060-2081. doi: $10.3390 /$ w7052060

Maynard LA, Loosli JK (1969) Animal nutrition. McGraw-Hill, New York

Mesplé F, Troussellier M, Casellas C, Legendre P (1996) Evaluation of simple statistical criteria to qualify a simulation. Ecol Modell 88:9-18. doi: 10.1016/0304-3800(95)00033-X

Murphy MD, Taylor RG (1990) Reproduction, growth, and mortality of red drum Sciaenops ocellatus in Florida waters. Fish Bull 88:531-542

Neill H (1990) Environmental requirements of red drum. In: Chamberlain G, Miget R, Haby M (eds) Red drum aquaculture. Texas A \& M University Sea Grant, Galveston, pp 105-108

Neill WH, Scott Brandes T, Burke BJ, et al (2004) Ecophys.Fish: A Simulation Model of Fish Growth in TimeVarying Environmental Regimes. Rev Fish Sci 12:233-288. doi: 10.1080/10641260490479818

Paquotte P (1998) Red-drum (Sciaenops ocellata) farming in Martinique: a new prospect for Caribbean marine aquaculture ? In: IIFET Conference. Tromso, pp 1-7

Pauly D (1979) Gill size and temperature as governing factors in fish growth: a generalization of von Bertalanffy's growth formula. Kiel, Germany

Pilati A, Vanni MJ (2007) Ontogeny, diet shifts, and nutrient stoichiometry in fish. Oikos 116:1663-1674. doi: 10.1111/j.0030-1299.2007.15970.x

Porch C, Wilson C, Nieland D (2002) A new growth model for red drum (Sciaenops ocellatus) that accomodates seasonal and ontogenetic changes in growth rates. Fish Bull 100:149-152

R Core Team (2018) R: A language and environment for statistical computing.

Reid GK, Liutkus M, Robinson SMC, et al (2009) A review of the biophysical properties of salmonid faeces: implications for aquaculture waste dispersal models and integrated multi-trophic aquaculture. Aquac Res 40:257-273. doi: 10.1111/j.1365-2109.2008.02065.x

Ross JL, Stevens TM, Vaughan DS (1995) Age, Growth, Mortality, and Reproductive Biology of Red Drums in North Carolina Waters. Trans Am Fish Soc 124:37-54. doi: 10.1577/15488659(1995)124<0037:AGMARB>2.3.CO;2

Sandifer PA, Hopkins JS, Stokes AD, Smiley RD (1993) Experimental pond grow-out of red drum, Sciaenops ocellatus, in South Carolina. Aquaculture 118:217-228. doi: 10.1016/0044-8486(93)90458-B

Soto D, Aguilar-Manjarrez J, Brugère C, et al (2008) Applying an ecosystem-based approach to aquaculture: principles, scales and some management measures. In: Soto D, Aguilar-Manjarrez J, Hishamunda N (eds) Building an ecosystem approach to aquaculture. FAO/Universitat de les Illes Balears Expert Workshop. 7-11 May 2007, Palma de Mallorca, Spain. FAO Fisheries and Aquaculture Proceedings, Rome, pp 15-35

Sousa T, Domingos T, Poggiale J-C, Kooijman SALM (2010) Dynamic energy budget theory restores coherence in biology. Philos Trans R Soc Lond B Biol Sci 365:3413-28. doi: 10.1098/rstb.2010.0166

Stigebrandt A, Aure J, Ervik A, Hansen PK (2004) Regulating the local environmental impact of intensive marine fish farming. Aquaculture 234:239-261. doi: 10.1016/j.aquaculture.2003.11.029

Strain PM, Hargrave BT (2005) Salmon Aquaculture, Nutrient Fluxes and Ecosystem Processes in 
Southwestern New Brunswick. Environ Eff Mar Finfish Aquac 5:29-57. doi: 10.1007/b136003

Sun M, Hassan SG, Li D (2016) Models for estimating feed intake in aquaculture: A review. Comput Electron Agric 127:425-438. doi: 10.1016/j.compag.2016.06.024

Tantikitti C, Sangpong W, Chiavareesajja S (2005) Effects of defatted soybean protein levels on growth performance and nitrogen and phosphorus excretion in Asian seabass (Lates calcarifer). Aquaculture 248:41-50. doi: 10.1016/J.AQUACULTURE.2005.04.027

van der Meer J (2006) An introduction to Dynamic Energy Budget (DEB) models with special emphasis on parameter estimation. J Sea Res 56:85-102. doi: 10.1016/j.seares.2006.03.001

von Bertalanffy L (1957) Quantitative laws in metabolism and growth. Q Rev Biol 32:217-231. doi: 10.1086/401873

Wang X, Olsen L, Reitan K, Olsen Y (2012) Discharge of nutrient wastes from salmon farms: environmental effects, and potential for integrated multi-trophic aquaculture. Aquac Environ Interact 2:267-283. doi: 10.3354/aei00044

Xu Z, Lin X, Lin Q, et al (2007) Nitrogen, phosphorus, and energy waste outputs of four marine cage-cultured fish fed with trash fish. Aquaculture 263:130-141. doi: 10.1016/J.AQUACULTURE.2006.10.020 


\section{Figure legends}

Figure 1. Conceptual framework of the FINS model, combining a farm production module (individual and population growth submodels) and a waste emission module (macromolecule mass balance submodel) to estimate farm production, feed intake and waste emissions. Feed composition, fish composition and apparent digestibility coefficients (ADCs) are defined at the macromolecule level. FINS's outputs can be calculated for any day during a routine year of production or summed over a period.

Figure 2. Biomass dynamics during routine operations for the Small farm simulated by the FINS model. Square section is the routine production year in Small farm. Decreasing biomass in each cohort after six months is due to gradual increasing harvests volumes during the six last months of the culture cycle.

Figure 3. a) Water temperature and b) dissolved oxygen concentrations at experimental facilities in Martinique (Le Robert) and near a fish farm in Mayotte (Longoni Bay). Data were averaged over "n" years of annual data collected from 2008-2017.

Figure 4. Red drum (Sciaenops ocellatus) growth predictions (-) from the generalized Von Bertalanffy Growth Model (VBGM) compared to the dataset of captive individuals $(n=308)$ reared in Martinique used to calibrate the model $(\bullet)$ and to field data from fish farms in Mayotte $(\Delta)(\mathrm{n}=12)$. VBGM equation is $W(t)=W_{\infty} \times\left(1-e^{-k\left(t-t_{0}\right)}\right)^{p}$ with $\mathrm{W}$, individual fish weight; $\mathrm{W} \infty$, asymptotic weight; $\mathrm{t}$, individual fish age; $\mathrm{t} 0$, initial age; $\mathrm{k}$, relative growth rate; $\mathrm{p}$, dimensionless factor.

Figure 5. Parameter sensitivity analysis performed for two model outputs: total solid waste and dissolved $\mathrm{P}$ emissions. The normalized sensitivity index (S) was calculated by dividing the relative change in model output by the relative change in the parameter value. Parameters with little influence $(\mathrm{S}<0.1)$ are not plotted. $\mathrm{k}$, relative growth rate; $\tau_{\text {loss }}$, mortality rate; $\mathrm{SD}$, maximum stocking density; DFR, daily feeding rate; $\delta_{u}$, proportion of uneaten feed; $\mathrm{N}_{i \text { feed, }}$ macromolecule or $\mathrm{P}$ content in feed; 
$\mathrm{DM}_{\text {feed }}$, dry matter content in feed; $\mathrm{ADC}_{i}$, macromolecule or $\mathrm{P}$ apparent digestibility coefficient; $\mathrm{N}_{P \text { fish }}$, $\mathrm{P}$ content in fish.

Figure 6. Solid waste and C, N, P mass balance for three red drum farm scenarios: Small, Medium and Large farm scale. Values are expressed as kg per t of fish harvested during a routine year of production. In the below frames, solid emissions (dry weight) including feces calculated from apparent digestibility coefficients (ADCs) using either feed dry weight ADC or macromolecule ADCs considering protein, lipid, carbohydrate (sugars and starch), fiber and ash fractions and uneaten feed. 


\section{Tables}

Table 1. Equations used in the Farm productIon and Nutrient emiSsions (FINS) model to predict red drum fish farming production and waste emissions.

\begin{tabular}{|c|c|c|c|}
\hline Model equation & Eq. & Variable and parameters & Units \\
\hline $\begin{array}{l}\text { Farm production module } \\
\text { Individual growth (Von Bertalanffy growth model) } \\
W(t)=W_{\infty} \times\left(1-e^{-k\left(t-t_{0}\right)}\right)^{p}\end{array}$ & (1) & $\begin{array}{l}\text { W: Individual fish weight } \\
W_{\infty}: \text { Asymptotic weight } \\
\text { t: Individual fish age } \\
\text { to: Initial age } \\
\text { k: Relative growth rate } \\
\text { p: Dimensionless factor }\end{array}$ & $\begin{array}{ll}\mathrm{kg} \mathrm{fresh} \text { weight } \\
(\mathrm{FW}) & \\
\mathrm{kg} \mathrm{FW} & \\
\text { day } & \\
\text { day } & \\
\text { day }^{-1} & \\
- & \end{array}$ \\
\hline $\begin{array}{l}\text { Population size } \\
\frac{d N(t)}{d t}=\left(-\tau_{\text {mort }}-\tau_{\text {loss }}-\tau_{\text {harvest }}\right) \times N(t)\end{array}$ & $(2)$ & $\begin{array}{l}\mathrm{t}: \text { Rearing time in cages } \\
\mathrm{N}_{\mathrm{t}}: \text { Number of individuals per lot } \\
\tau_{\text {mort }}: \text { Mortality rate } \\
\tau_{\text {loss }}: \text { Loss rate } \\
\tau_{\text {harvest }}: \text { Harvest rate }\end{array}$ & $\begin{array}{l}\text { day } \\
\% \cdot \text { day }^{-1} \\
\% \cdot \text { day }^{-1} \\
\% \cdot \text { day }^{-1}\end{array}$ \\
\hline $\begin{array}{l}\text { Biomass per lot } \\
B(t)=N(t) \times W(t)\end{array}$ & (3) & B: Biomass per lot & kg FW \\
\hline $\begin{array}{l}\text { Feed inputs } \\
Q_{f}(t)=\int_{0}^{t} B(t) \times D F R(t) \times d t\end{array}$ & (4) & $\begin{array}{l}\text { Qf: Quantity of feed distributed } \\
\text { DFR: Daily feeding rate }\end{array}$ & $\begin{array}{l}\mathrm{kg} \mathrm{FW} \\
\% \text { of biomass.day }{ }^{-1}\end{array}$ \\
\hline $\begin{array}{l}\text { Waste emission module } \\
\text { Macromolecule mass balance } \\
Q_{i}(t)=N_{\text {ifeed }} \times Q_{f}(t) \times D M_{\text {feed }}\end{array}$ & (5) & $\begin{array}{l}\text { Q }: \text { Macromolecule or } \mathrm{P} \text { inputs } \\
\text { distributed } \\
N_{\text {ifeed }}: \text { Macromolecule or } \mathrm{P} \text { content in } \\
\text { feed } \\
D M_{\text {feed }}: \text { Dry matter content in feed }\end{array}$ & $\begin{array}{l}\mathrm{kg} \\
\% \\
\%\end{array}$ \\
\hline$W_{i}(t)=N_{i f e e d} \times \delta_{u} \times Q_{f}(t)$ & (6) & $\begin{array}{l}\mathrm{W}_{\mathrm{i}} \text { : Macromolecule or P loss from } \\
\text { uneaten feed } \\
\delta_{u} \text { : Percentage of feed uneaten }\end{array}$ & $\begin{array}{l}\mathrm{kg} \\
\%\end{array}$ \\
\hline$F_{i}(t)=\left(Q_{i}(t)-W_{i}(t)\right) \times\left(1-A D C_{i}\right)$ & (7) & $\mathrm{F}_{\mathrm{i}}$ : Fecal macromolecule or $\mathrm{P}$ emissions & $\mathrm{kg}$ \\
\hline $\begin{array}{l}S_{i}(t)=W_{i}(t)+F_{i}(t) \\
D_{i}(t)=1-F_{i}(t)-G_{i}\end{array}$ & $\begin{array}{l}(8) \\
(9)\end{array}$ & 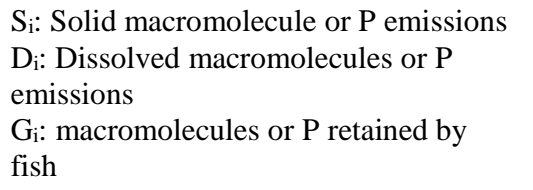 & $\begin{array}{l}\mathrm{kg} \\
\mathrm{kg} \\
\mathrm{kg}\end{array}$ \\
\hline $\begin{array}{l}\text { Elemental composition in macromolecules } \\
\begin{array}{l}C=0.5 \times N_{\text {proteins }}+0.4 \times N_{\text {carbohydrates }}+0.4 \\
\times N_{\text {fibers }}+0.7 \times N_{\text {lipids }}\end{array}\end{array}$ & $(10)$ & $\begin{array}{l}C: \text { Carbon content in feces, feed or fish } \\
\text { from macromolecules }\end{array}$ & $\%$ \\
\hline$N=0.16 \times N_{\text {proteins }}$ & (11) & $\begin{array}{l}N \text { : Nitrogen content in feces, feed or fish } \\
\text { from macromolecules }\end{array}$ & $\%$ \\
\hline $\begin{array}{l}\text { Digestibility coefficient } \\
\qquad A D C_{i}=100 \times\left(1-\frac{Y_{\text {feed }}}{Y_{\text {feces }}} \times \frac{N_{i \text { feces }}}{N_{i \text { feed }}}\right)\end{array}$ & $(12)$ & $\begin{array}{l}\text { ADC } \mathrm{i} \text { : Apparent digestibility coefficient } \\
Y_{\text {feed }} \text { Yttrium oxide content in feed } \\
\mathrm{Y}_{\text {feces: }} \text { Yttrium oxide content in feces } \\
N_{i \text { feces }} \text { : Macromolecule or P content in } \\
\text { feces }\end{array}$ & $\begin{array}{l}\% \\
\% \\
\% \\
\%\end{array}$ \\
\hline
\end{tabular}


Table 2. Proximate composition of feed, feces and whole fish body samples used to determine apparent digestibility coefficients (ADC) of red drum with NUTRIMarine 6.0 pellets after coating with yttrium oxide. Mean values ( \pm 1 standard deviation) for three experimental groups are given.

\begin{tabular}{|c|c|c|c|c|c|}
\hline Composition & $\begin{array}{l}\text { Feed } \\
(\mathrm{n}=1)\end{array}$ & $\begin{array}{l}\text { Feces } \\
(\mathrm{n}=3)\end{array}$ & $\begin{array}{l}\text { Fish body } \\
(\mathrm{n}=3)\end{array}$ & $\begin{array}{l}\mathrm{ADC} \\
(\mathrm{n}=3)\end{array}$ & Unit \\
\hline Dry weight (DW) & 96.2 & - & $\begin{array}{l}29.8 \pm 0.3^{\mathrm{a}} \\
30.3 \pm 0.1^{\mathrm{b}}\end{array}$ & $77.96 \pm 1.08$ & $(\%)$ \\
\hline Protein & 47.8 & $13.4 \pm 0.8$ & $\begin{array}{l}57.8 \pm 0.7^{\mathrm{a}} \\
59.6 \pm 0.9^{\mathrm{b}}\end{array}$ & $93.80 \pm 0.68$ & $(\% \mathrm{DW})$ \\
\hline Lipids & 13.1 & $3.6 \pm 0.9$ & $\begin{array}{l}22.8 \pm 1.0^{\mathrm{a}} \\
22.0 \pm 1.1^{\mathrm{b}}\end{array}$ & $94.00 \pm 1.49$ & $(\% \mathrm{DW})$ \\
\hline Sugars & 2.54 & $0.10 \pm 0.00$ & $\begin{array}{l}0.13 \pm 0.06^{\mathrm{a}} \\
0.03 \pm 0.03^{\mathrm{b}}\end{array}$ & $99.10 \pm 0.09$ & $(\% \mathrm{DW})$ \\
\hline Starch & 12.5 & $11.7^{\mathrm{c}}$ & - & $79.30 \pm 1.01$ & $(\% \mathrm{DW})$ \\
\hline Fiber & 8.8 & $35.0 \pm 2.1$ & - & $11.88 \pm 3.40$ & $(\% \mathrm{DW})$ \\
\hline Ash & 8.6 & $25.1 \pm 0.7$ & $\begin{array}{l}13.9 \pm 0.2^{\mathrm{a}} \\
13.6 \pm 0.5^{\mathrm{b}}\end{array}$ & $32.60 \pm 1.87$ & $(\% \mathrm{DW})$ \\
\hline Phosphorus & 1.2 & $1.6 \pm 0.1$ & $\begin{array}{l}2.6 \pm 0.1^{\mathrm{a}} \\
2.6 \pm 0.1^{\mathrm{b}}\end{array}$ & $69.14 \pm 2.40$ & $(\% \mathrm{DW})$ \\
\hline
\end{tabular}

Initial body composition

${ }^{b}$ Final body composition

${ }^{c}$ Fecal samples were pooled to obtain enough material to analyze starch 
Table 3. Input data and output of three red drum farming scenarios (Small, Medium and Large) predicted by the Farm productIon and Nutrient emiSsions model (FINS), with seeding set to reach a maximum stocking density of $20 \mathrm{~kg} \mathrm{~m}^{-3}$ during the culture cycle.

\begin{tabular}{|c|c|c|c|c|}
\hline Characteristic & Small & Medium & Large & Unit \\
\hline \multicolumn{5}{|l|}{ Farm inputs } \\
\hline Feed & 34.94 & 589.48 & 3229.72 & t dry weight. $\mathrm{yr}^{-1}$ \\
\hline Seeds & 172 & 949 & 9166 & $\mathrm{~kg} \cdot \mathrm{yr}^{-1}$ \\
\hline \multicolumn{5}{|l|}{ Farm outputs } \\
\hline Fish harvested & 22.88 & 298.58 & 2078.60 & t. $\mathrm{yr}^{-1}$ \\
\hline Dead and lost fish & 4.29 & 47.94 & 183.53 & t. $\mathrm{yr}^{-1}$ \\
\hline \multicolumn{5}{|l|}{ Farming performances } \\
\hline Mean weight of harvested fish & 1.11 & 2.56 & 1.54 & $\mathrm{~kg}$ \\
\hline $\mathrm{FCR}_{\bmod ^{\mathrm{a}}}$ & 1.54 & 1.91 & 1.56 & \\
\hline Cohort return rate ${ }^{b}$ & 66 & 73 & 81 & $\%$ \\
\hline Fish harvest yields & 26.48 & 18.14 & 21.98 & $\mathrm{~kg}$ of fish harvested. $\mathrm{m}^{-3} \cdot \mathrm{yr}^{-1}$ \\
\hline $\begin{array}{l}{ }^{\mathrm{a}} \text { Feed Conversion Ratio }(\mathrm{FCR})=\mathrm{F} \\
\text { seeded (in fresh weight) } \\
\text { beturn rate }(\%)=\text { (Number of fish }\end{array}$ & tributed ( & $\begin{array}{l}\text { y weight) } \\
\text { of fish se }\end{array}$ & $\begin{array}{l}\text { Fish biom } \\
\text { d) } \times 100\end{array}$ & arvested - Fish biomass \\
\hline
\end{tabular}




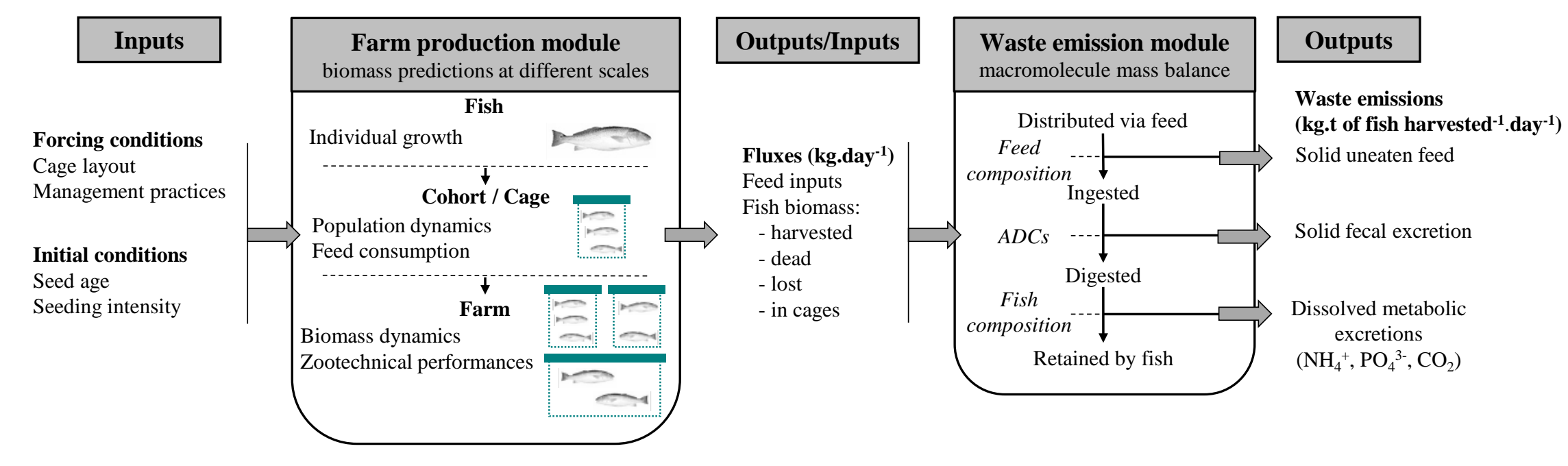




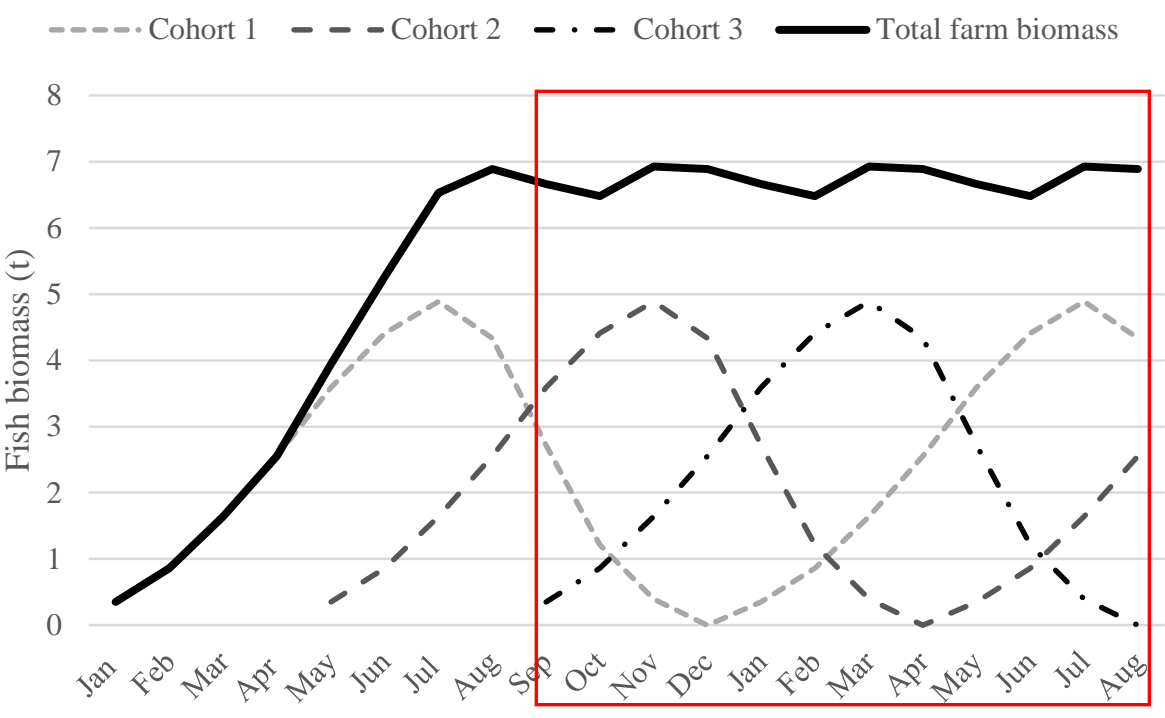

Dynamics of fish biomass during

routine operations on the Small farm 


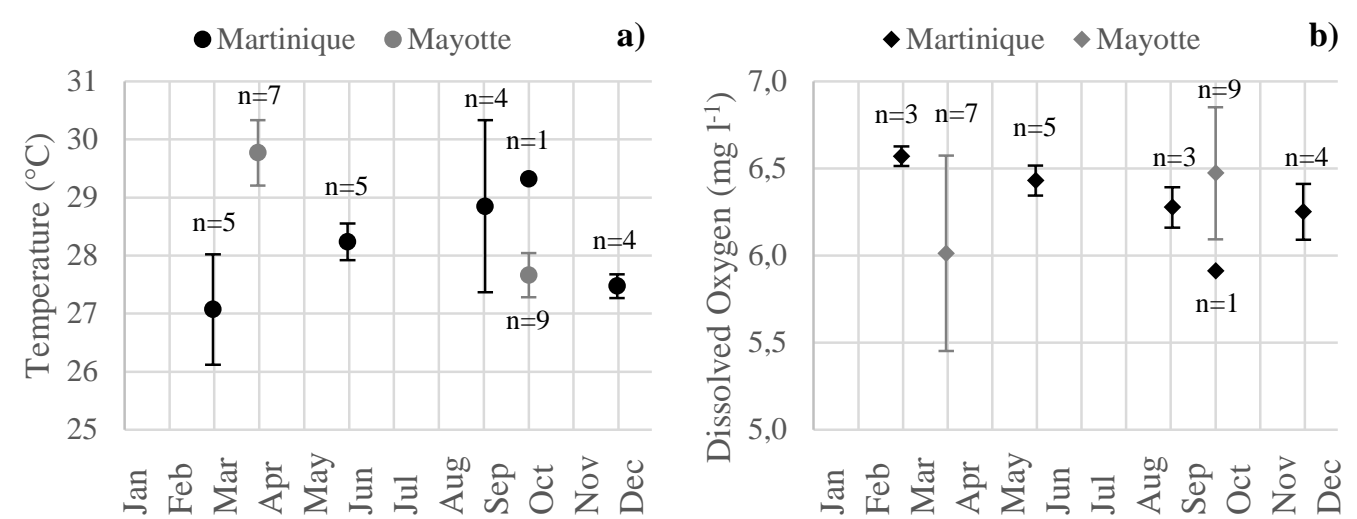




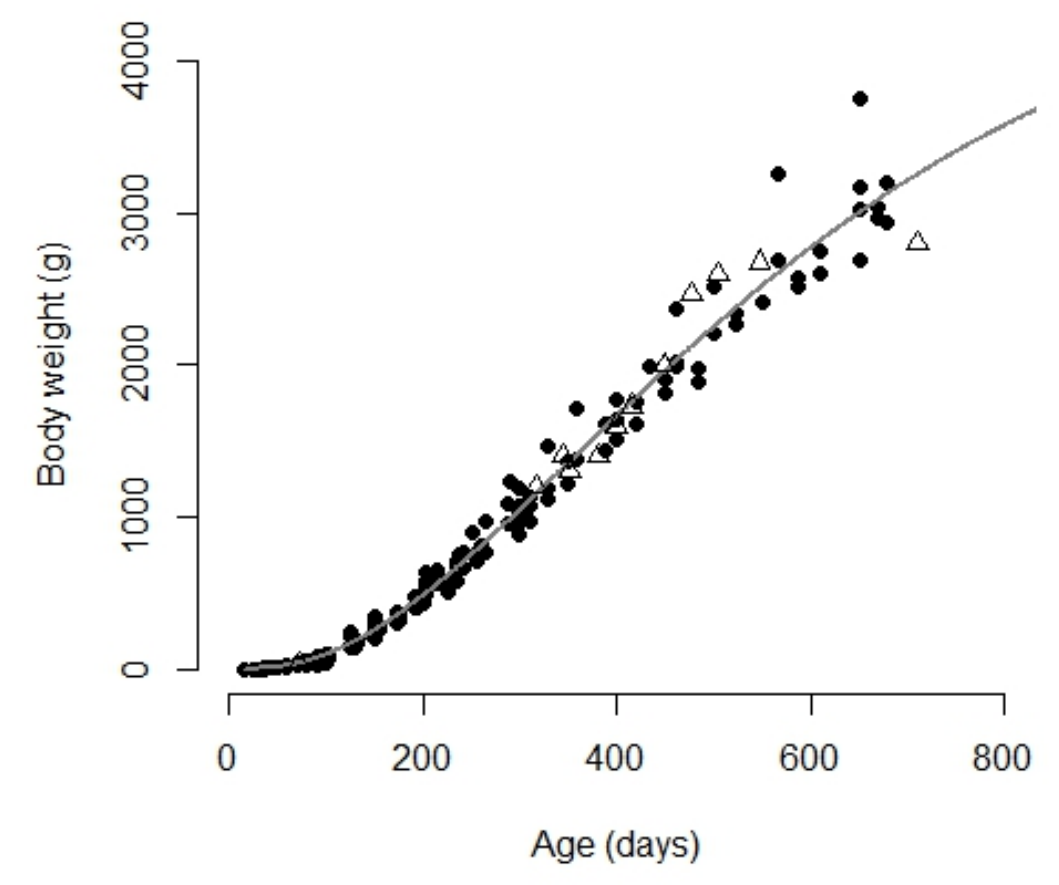



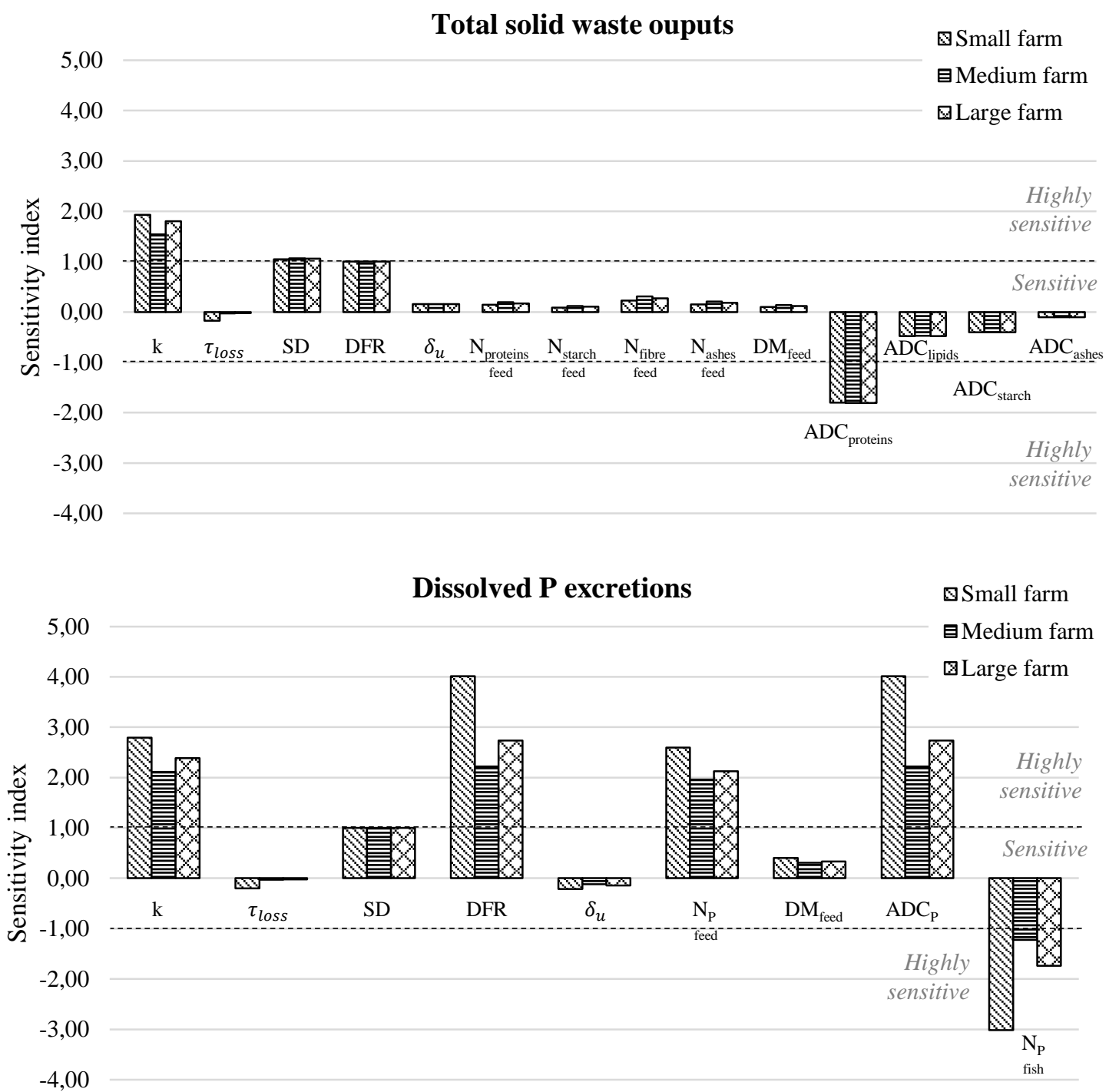


\section{Small farm}

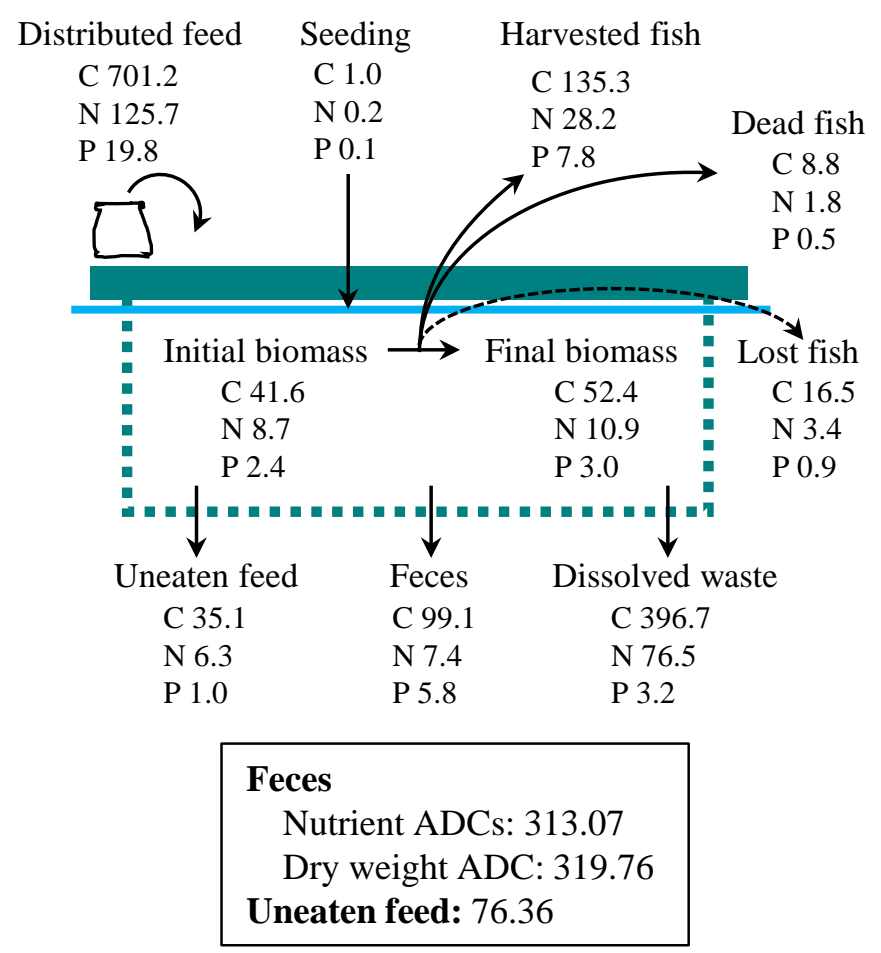

\section{Medium farm}

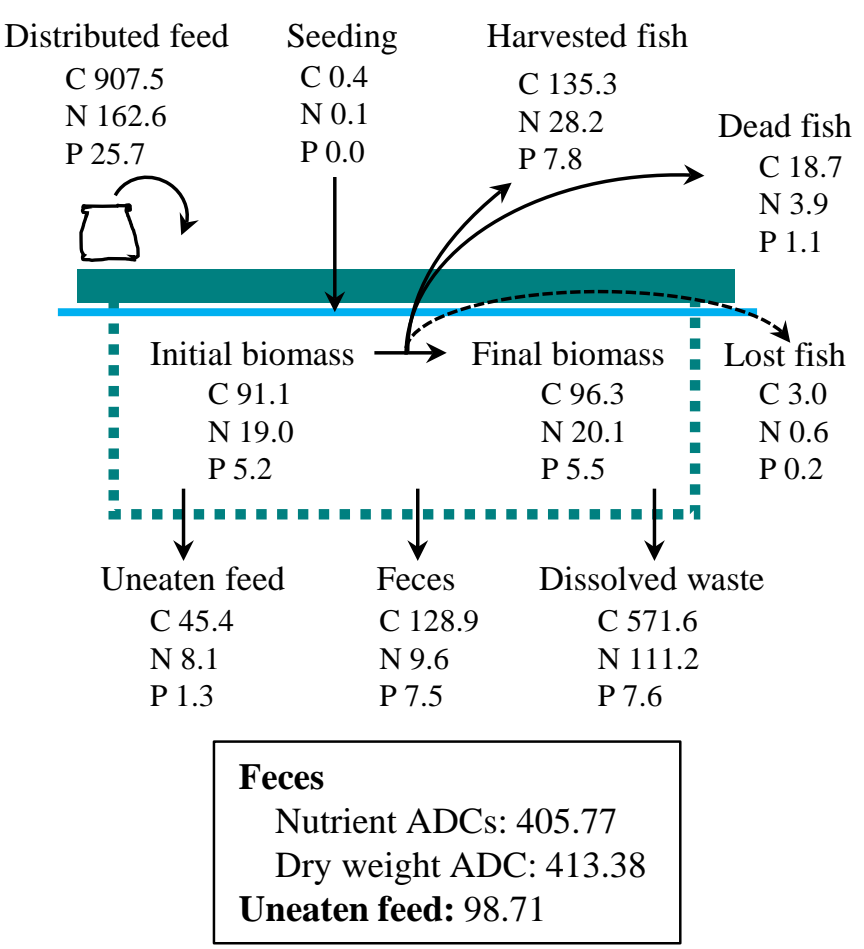

\section{Large farm}

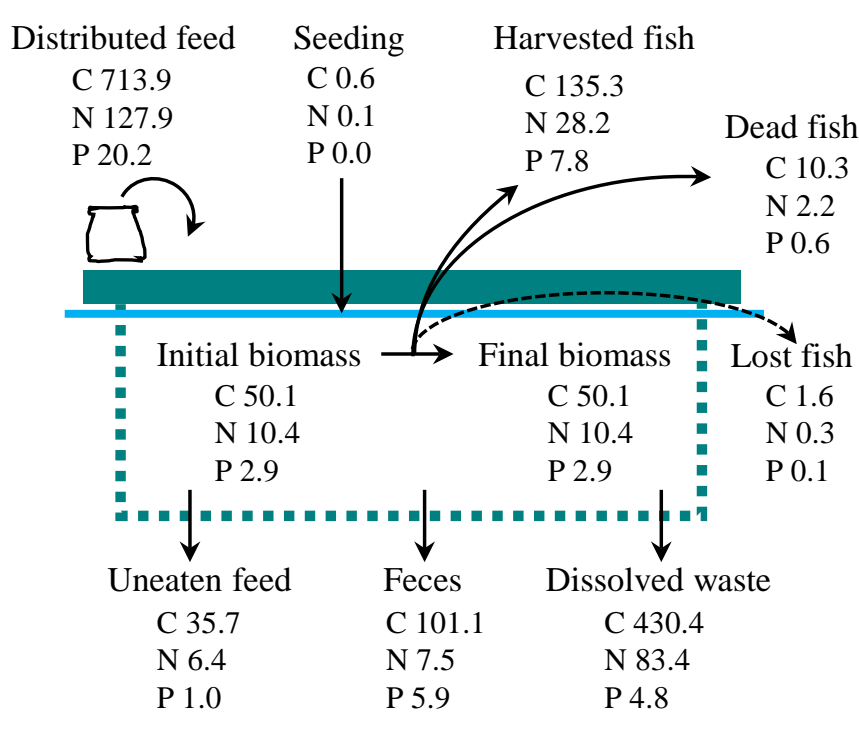

Feces

Nutrient ADCs: 318.96

Dry weight ADC: 325.33

Uneaten feed: 78.10 